\title{
Shifter Device
}

National Cancer Institute

\section{Source}

National Cancer Institute. Shifter Device. NCI Thesaurus. Code C50173.

A mechanical device designed to change the gears in a mechanism. 